Masja Leendertse

Rob J. Willems

Ida A. Giebelen

Sandrine Florquin

Petra S. van den Pangaart

Marc J. Bonten

Tom van der Poll

\title{
Cecal ligation and puncture induced sepsis
impairs host defense against Enterococcus \\ Cecal ligation and puncture induced sepsis
impairs host defense against Enterococcus faecium peritonitis
}

Received: 1 September 2008

Accepted: 23 January 2009

Published online: 17 February 2009

(C) The Author(s) 2009. This article is published with open access at Springerlink.com
M. Leendertse - I. A. Giebelen . P. S. van den Pangaart . T. van der Poll Center for Infection and Immunity Amsterdam (CINIMA), Academic Medical Center, Amsterdam, The Netherlands

M. Leendertse ( $\square)$. I. A. Giebelen . P. S. van den Pangaart . T. van der Poll Center for Experimental and Molecular Medicine, Academic Medical Center, G2-130, Meibergdreef 9,

1105 AZ Amsterdam, The Netherlands

e-mail: m.leendertse@amc.uva.nl

Tel.: +31-20-5669111

Fax: +31-20-6977192

\section{S. Florquin}

Department of Pathology,

Academic Medical Center, Amsterdam, The Netherlands

M. Leendertse · R. J. Willems ·
M. J. Bonten
Department of Medical Microbiology,
University Medical Center Utrecht,
Utrecht, The Netherlands
M. J. Bonten
Julius Center for Health Studies
and Primary Care, University Medical
Center Utrecht, Utrecht, The Netherlands

Abstract Purpose: Multiresistant and vancomycin resistant Enterococcus faecium (VRE) can cause serious infections in hospitalized patients with various co-morbid diseases. We investigated the course of VRE peritonitis after cecal ligation and puncture (CLP)-induced sepsis and compared this to sham operated mice. Methods: Mice were subjected to CLP or sham surgery. Forty-eight hours thereafter four groups were created by subjecting mice to peritoneal injection of either VRE or saline. Results: Mice infected with VRE after CLP were severely impaired in eliminating VRE from the peritoneal cavity and distant body sites. These mice failed to mount an early inflammatory response at the primary site of VRE infection. VRE superinfection did not influence CLPinduced organ damage or polymicrobial bacterial loads.

Conclusions: Sublethal polymicrobial sepsis greatly facilitates infection and dissemination of VRE. VRE does not influence the course of CLPinduced sepsis.

Keywords Enterococcus faecium . Cecal ligation and puncture (CLP) . Innate immunity - Immunoparalysis . Sepsis - Mouse model

\section{Introduction}

Infections with multiresistant and vancomycin resistant Enterococcus faecium (VRE), are a growing problem worldwide [1]. Severe infections with VRE are almost exclusively found in immunocompromised patients, including patients at intensive care units suffering from different co-morbid conditions [2-4].

Patients who have survived the initial phase of sepsis demonstrate features consistent with immune depression.
It has been proposed that this immune suppression contributes to the enhanced susceptibility to nosocomial infections and late mortality of sepsis patients [5-11]. Cecal ligation and puncture (CLP) is considered a clinically relevant model to study the septic response [12]. Many studies that investigated the sepsis-induced state of immunoparalysis used the model of CLP, especially to examine host defense against secondary pneumonia [13-15]. VRE is often cultured from abdominal infections, frequently resulting in subsequent dissemination to 
blood and distant organs [16, 17]. To investigate the immune response to VRE infection we previously set up a model of VRE peritonitis in mice [18]. Healthy mice are able to mount an effective immune response in this model with peak cytokine levels after $2-6 \mathrm{~h}$ and an early peritoneal neutrophil influx, resulting in clearance of the systemic infection in 2-3 days. We here aimed to obtain insight into the innate immune response to VRE infection in an immunocompromised host, seeking to mimic the clinical scenario of abdominal sepsis with superimposed VRE peritonitis. For this, mice were subjected to CLP or sham surgery and subsequently infected with VRE intraperitoneally.

\section{Materials and methods}

Mice

Specific pathogen-free 10-week-old female C57BL/6 mice were purchased from Harlan Sprague-Dawley (Horst, The Netherlands). The Animal Care and Use Committee of the University of Amsterdam approved all experiments.

\section{Cecal ligation and puncture}

CLP was performed as previously described [19]. Mice were given buprenorphine $\left(\right.$ Temgesic $^{\circledR}$, ScheringPlough, Amstelveen, The Netherlands) $0.075 \mathrm{mg} / \mathrm{kg}$ subcutaneously $30 \mathrm{~min}$ preoperatively, and were anesthetized via inhalation of a mixture of $\mathrm{O}_{2}(1-2 \mathrm{l} / \mathrm{min})$ and isoflurane 2.0-2.5\% (Burtons, Kent, UK). During surgery mice were kept on a heating pad at $37^{\circ} \mathrm{C}$ (Animed, Barneveld, The Netherlands). A 1-cm midline incision was made on the abdomen, and the cecum was exposed. The distal $1 \mathrm{~cm}$ of the cecum was ligated with a 4-0 Vicryl suture (Ethicon, Johnson\&Johnson, St-Stevens-Woluwe, Belgium) and punctured throughand-through with a 26-gauge needle (BD, Drogheda, Ireland). A small amount of stool was extruded to ensure wound patency. The cecum was replaced and the abdomen was closed using Sofsilk 6-0 (Ethicon). This model results in a marked septic response and death in $0-10 \%$ of animals. Sham animals underwent an identical laparotomy; the cecum was exposed but not ligated or punctured and replaced. All mice were administered $1 \mathrm{ml}$ of sterile saline subcutaneously for fluid resuscitation post-operatively and $500 \mu \mathrm{l}$ saline twice daily thereafter, containing $0.05 \mathrm{mg} / \mathrm{kg}$ buprenorphine. Nine and eight mice were included in the CLP or sham group per time point, respectively.

\section{Induction of VRE peritonitis}

Forty-eight hours after surgery, VRE peritonitis was induced as previously described [18]. Mice were injected intraperitoneally with approximately $10^{8}$ colony-forming units (CFU) of VRE in $200 \mu \mathrm{l}$ sterile saline. Mice were killed $2 \mathrm{~h}, 1,2$ and 5 days thereafter.

\section{Bacterial strain}

VRE strain, E155, was used in all experiments. This clinical isolate from the Cook County Hospital, Chicago, IL, belongs to a genetic subpopulation of hospital-associated E. faecium that is responsible for the worldwide emergence of nosocomial multiresistant E. faecium, characterized by high-level quinolon and ampicillin resistance, a pathogenicity island, containing the variant esp gene, and the presence of five cell surface protein genes $[20,21]$.

\section{Collection of samples}

Mice were anesthetized by inhalation of isoflurane (Abbot, Laboratories Ltd., Kent, UK) $/ 0_{2}(2 \% / 21)$, a peritoneal lavage was performed with $5 \mathrm{ml}$ sterile phosphatebuffered-saline using a 18-gauge needle; peritoneal lavage fluid (PLF) was collected in sterile polypropylene tubes (BD, Breda, The Netherlands). Blood was drawn by cardiac puncture, transferred to heparin-gel vacutainer tubes and placed on ice. Liver and lungs were harvested. PLF supernatants and plasma were stored at $-20^{\circ} \mathrm{C}$ until further examination.

\section{Determination of bacterial outgrowth}

The number of VRE CFU was determined in PLF, blood, liver and lung homogenates. The organs were homogenized in four volumes of saline and serial tenfold dilutions were made of the homogenates, PLF and blood, then $50 \mu \mathrm{l}$ of each dilution was plated. Samples were plated on SlanetzBertley (SB) agar plates (Oxoid, Badhoevedorp, The Netherlands), supplemented with vancomycin $(6 \mu \mathrm{g} / \mathrm{ml})$, to determine the amount of VRE. No bacterial growth was observed when fecal pellets of naive mice were plated on these plates. Additionally, samples were plated onto BA, MacConkey (McC) (Difco, Detroit, MI) and colistin nalidixic acid (CNA) agar (BD, Breda, The Netherlands) for quantification of total aerobic, gram-negative and grampositive bacteria, respectively. The plates were incubated at $37^{\circ} \mathrm{C}$ under $5 \% \mathrm{CO}_{2}$, and $\mathrm{CFU}$ were counted after 20 (BA and $\mathrm{McC}$ ) or 44 (SB and CNA) hours. 
Cell counts and differentials

Total cell numbers were counted from each PLF sample using a hemocytometer (Beckman coulter, Fullerton, CA, USA). Differential cell counts were performed on cytospin preparations, stained with Giemsa (Diff-Quick; Dade Behring), by an investigator blinded for experimental groups.

Assays

Macrophage inflammatory protein (MIP)-2, cytokineinduced neutrophil chemoattractant $(\mathrm{KC})$ and LPSinduced $\mathrm{C}-\mathrm{X}-\mathrm{C}$ chemokine (LIX) were measured in PLF by ELISA's (R\&D Systems, Minneapolis, MN) according to the manufacturers' instructions. Tumor necrosis factor (TNF)- $\alpha$, interleukin (IL)-6, IL-10, IL$12 p 70$, interferon (IFN)- $\gamma$ and monocyte chemoattractant protein (MCP)-1 were measured in PLF and plasma by using a commercially available cytometric bead array (CBA) multiplex assay (BD Biosciences, San Jose, CA, USA) in accordance with the manufacturer's recommendations. Aspartate aminotransferase (ASAT) and creatinine were determined in plasma with commercially available kits (Sigma-Aldrich, St. Louis, MO, USA), using a Hittachi analyzer (Boehringer Mannheim, Mannheim, Germany).
Organ pathology

Livers and lungs were fixed in formaldehyde and embedded in paraffin for histological examination. Sections of $4 \mu \mathrm{m}$ were stained with hematoxylin-eosin, and analyzed by a pathologist blinded for groups. To score liver injury, interstitial inflammation, thrombi, hepatocellular necrosis and portal inflammation were analyzed. Lungs were scored for interstitial inflammation, edema, pleuritis and thrombi [22].

Statistical analysis

Data are expressed as mean \pm SEM. Serial data were analyzed by two-way analysis of variance (ANOVA) followed by a post hoc Bonferroni test. Two group comparisons were done by Mann-Whitney $U$ test. GraphPad Prism version 4 (GraphPad Software, San Diego, CA, USA) was used. A $P$-value $<0.05$ was considered statistically significant.

\section{Results}

CLP strongly impairs clearance of VRE

To obtain insight into the impact of abdominal sepsis on host defense against VRE, mice were intraperitoneally
Fig. 1 CLP causes a severe impairment in peritoneal and systemic clearance of $E$. faecium. Respectively, 8 and 9 mice per time point underwent sham surgery (triangles) or CLP (circles) and received an intraperitoneal injection with $10^{8}$ CFU E. faecium 48 h after the procedure. Two hours, 1, 2 and 5 days after $E$. faecium infection mice were killed. Mean $( \pm$ SEM) E. faecium CFU in a peritoneal lavage fluid (PLF), b blood, $\mathbf{c}$ liver, and $\mathbf{d}$ lung are shown. During the 5 days of the experiment $6 \%$ of the mice that underwent CLP and had a subsequent VRE infection died. $P$ values in figure represent the overall difference between groups; asterisks indicate differences between groups at one time point. $* P<0.05, * * P<0.01$, $* * * P<0.001$ compared to sham operated mice
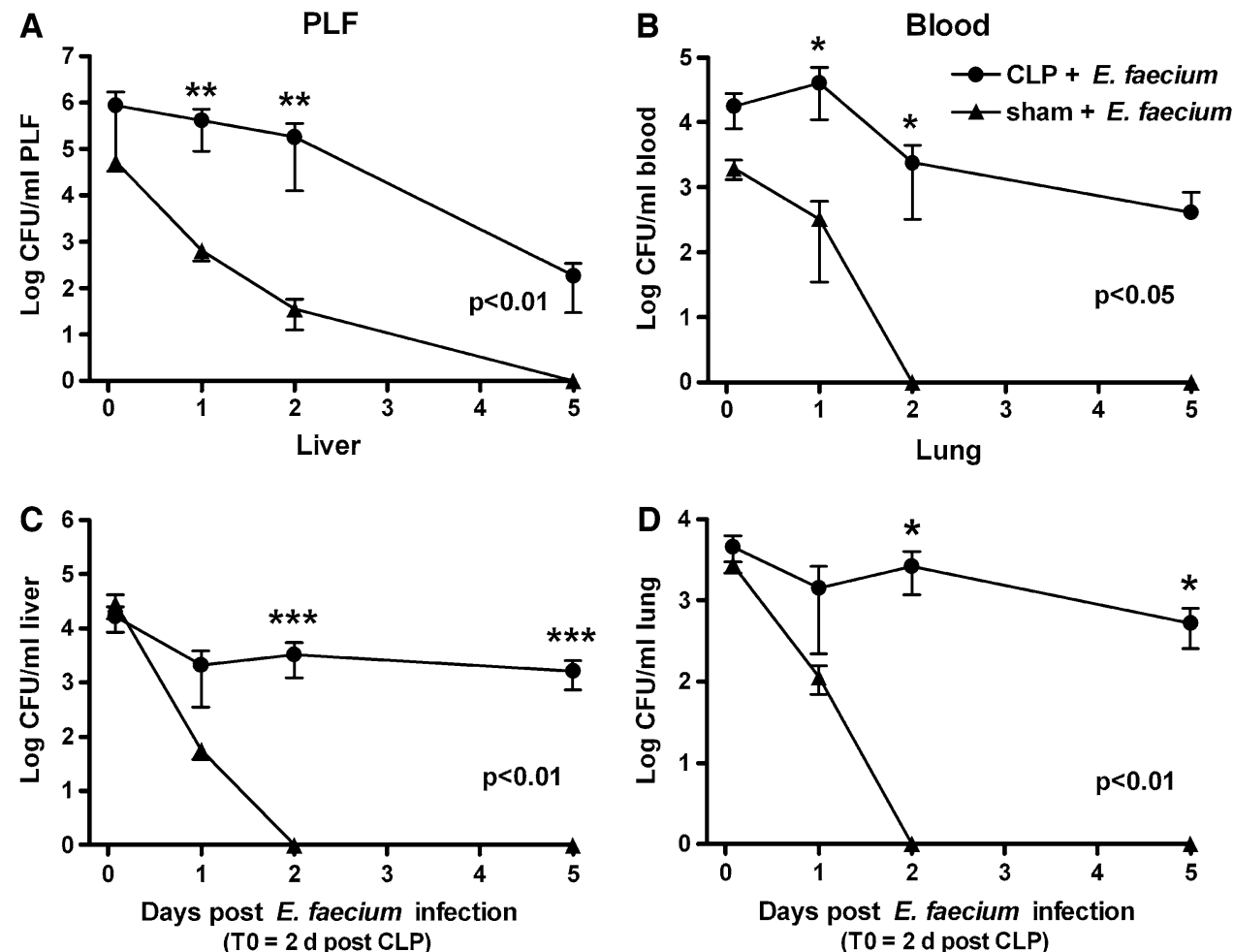
injected with a non-lethal amount of VRE $\left(10^{8} \mathrm{CFU}\right)$ or saline at $48 \mathrm{~h}$ after CLP or sham surgery. CLP was associated with a strongly impaired clearance of VRE in all organs examined (Fig. 1). Sham mice showed a rapid decline in enterococcal loads from the peritoneal cavity; 2 days after infection VRE could not be recovered anymore from blood, liver or lungs and only $2 / 8$ sham mice still had VRE in their peritoneal cavity. In contrast, in CLP mice enterococcal loads remained high in all body compartments examined for up to 5 days; 2 days after infection VRE loads were $>1,000$-fold higher in PLF, blood, liver and lungs of mice that had undergone CLP.

CLP results in a diminished neutrophil influx in response to VRE peritonitis

Peritoneal leukocyte counts and differentials did not differ significantly between CLP and sham mice $48 \mathrm{~h}$ after the procedure (directly before infection with VRE) (Fig. 2a, b). Sham mice demonstrated a strong and rapid increase in neutrophil counts in PLF peaking $2 \mathrm{~h}$ after infection with VRE. In contrast, CLP mice did not respond with an influx of neutrophils to the primary site of VRE infection, and neutrophil counts remained undistinguishable from CLP mice not infected with VRE (Fig. 2a). Peritoneal neutrophil numbers increased in all CLP mice later on irrespective of VRE infection, as a consequence of the CLP induced polymicrobial peritonitis [23]. After infection with VRE, both sham and CLP mice had an initial drop in macrophage numbers, followed by an increase after $24 \mathrm{~h}$ (Fig. 2b). CLP mice not infected with VRE had no significant change in macrophage numbers during this period. Sham mice injected with saline did not show any important changes in peritoneal cell numbers and differentials. CLP mice displayed highest numbers of neutrophils and macrophages at $48 \mathrm{~h}$ after VRE or saline injection (not shown). At 5 days peritoneal cells from all mice were back to naïve levels (not shown).

The murine CXC chemokines KC, MIP-2 and LIX are known neutrophil attracting and activating mediators. Sham mice responded with an increase in KC and LIX levels $2 \mathrm{~h}$ after VRE infection (Fig. 2c, d), whereas CLP mice subsequently infected did not. MIP-2 levels were low in all mice (not shown). Sham mice not infected with VRE showed low or undetectable chemokine levels throughout the entire experiment (not shown).

CLP causes an impaired peritoneal cytokine response to VRE peritonitis

At $48 \mathrm{~h}$ after CLP, directly before the administration of VRE, plasma and PLF concentrations of TNF- $\alpha$, IL- 6 ,
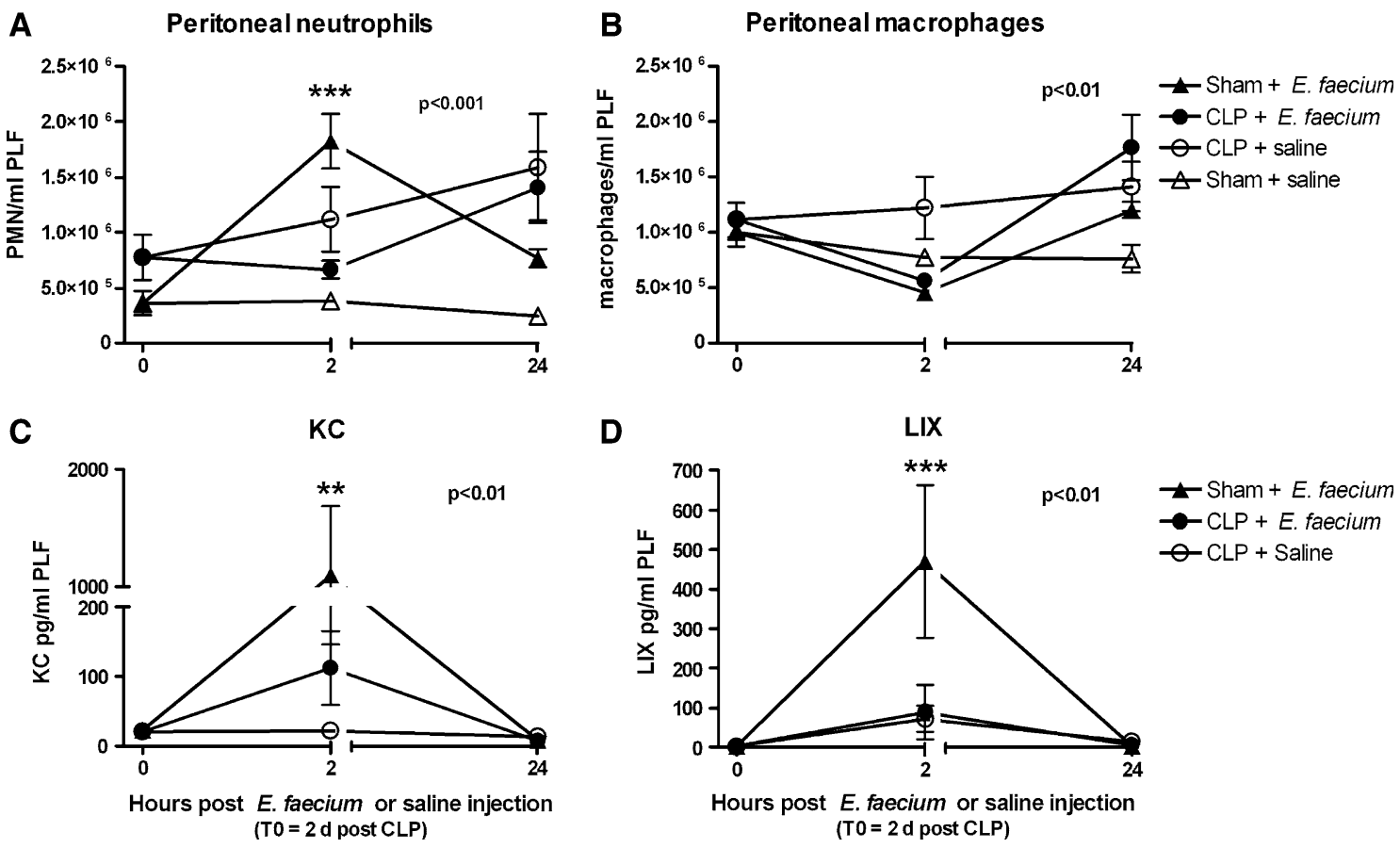

Fig. 2 CLP results in reduced peritoneal neutrophil influx and CXC chemokine release. Mean $( \pm$ SEM) of peritoneal neutrophil (a) and macrophage (b) counts and $\mathrm{KC}$ (c) and LIX (d) concentrations. Mice were challenged with $10^{8} \mathrm{CFU}$ E. faecium (closed symbols) or saline (open symbols) $48 \mathrm{~h}$ after CLP (circles), or sham surgery (triangles). Data are shown for 0,2 and $24 \mathrm{~h}$ after

E. faecium or saline injection. $N=8-9$ mice per group at each time point. $P$ values in figure represent the overall difference between groups; asterisks indicate differences between groups at one time point. $* * P<0.01, * * * P<0.001$ compared to sham operated and E. faecium infected mice 
Fig. 3 CLP causes a reduced peritoneal, but not plasma cytokine response to $E$. faecium infection. Mean $( \pm$ SEM $)$ of peritoneal (a-d) and plasma (e-h) cytokine levels. Mice received $10^{8}$ CFU E. faecium (closed circles) or saline (open circles) intraperitoneally $48 \mathrm{~h}$ after CLP, or E. faecium after sham surgery (triangles). TNF$\alpha$, IL-6, IL-10 and MCP-1 levels are shown for $T=0$ (directly before E. faecium or saline injection) and 2 and $24 \mathrm{~h}$ thereafter. $N=8-9$ per group at each time point. $P$ values in figure represent the overall difference between groups; asterisks indicate differences between groups at one time point. $* * P<0.01$,

$* * * P<0.001$ compared to sham operated and E. faecium infected mice
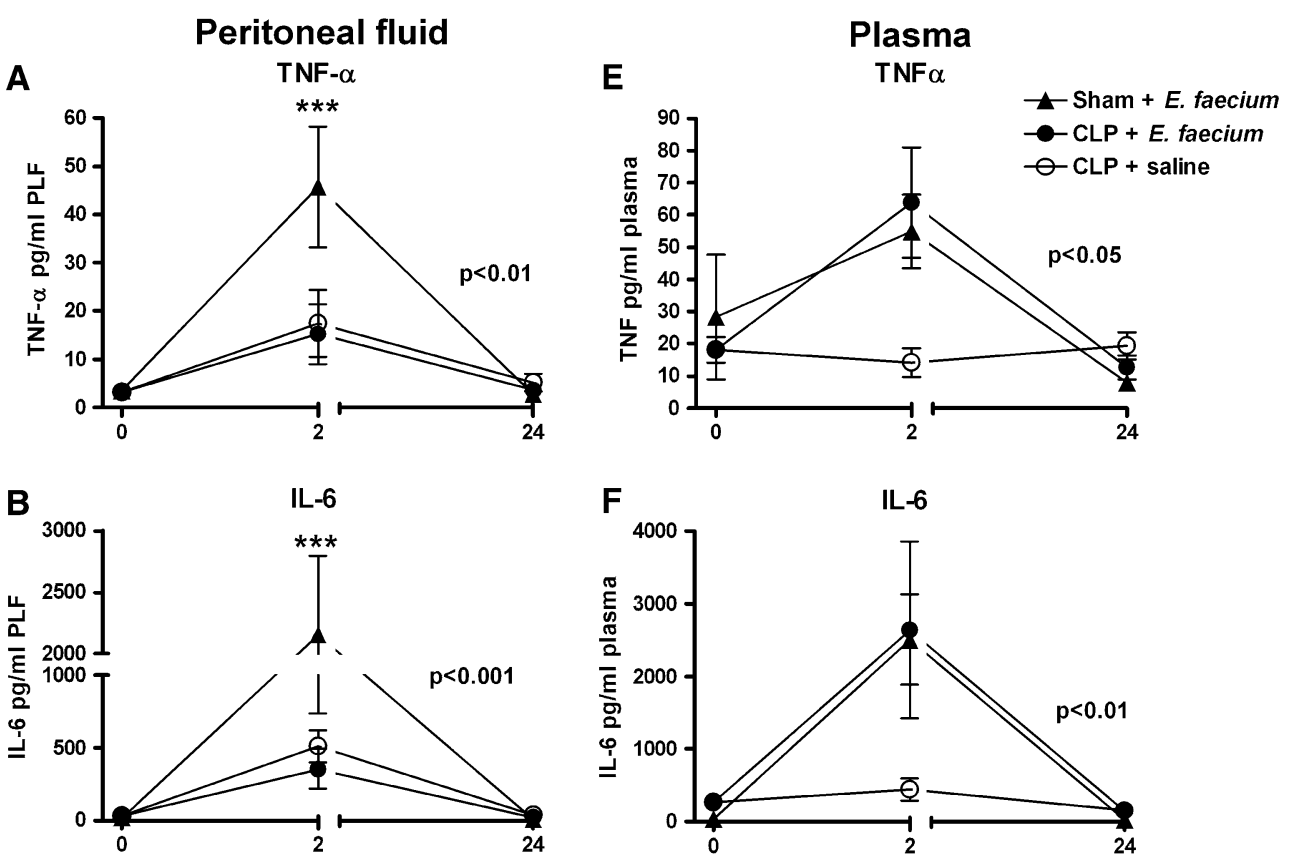

F
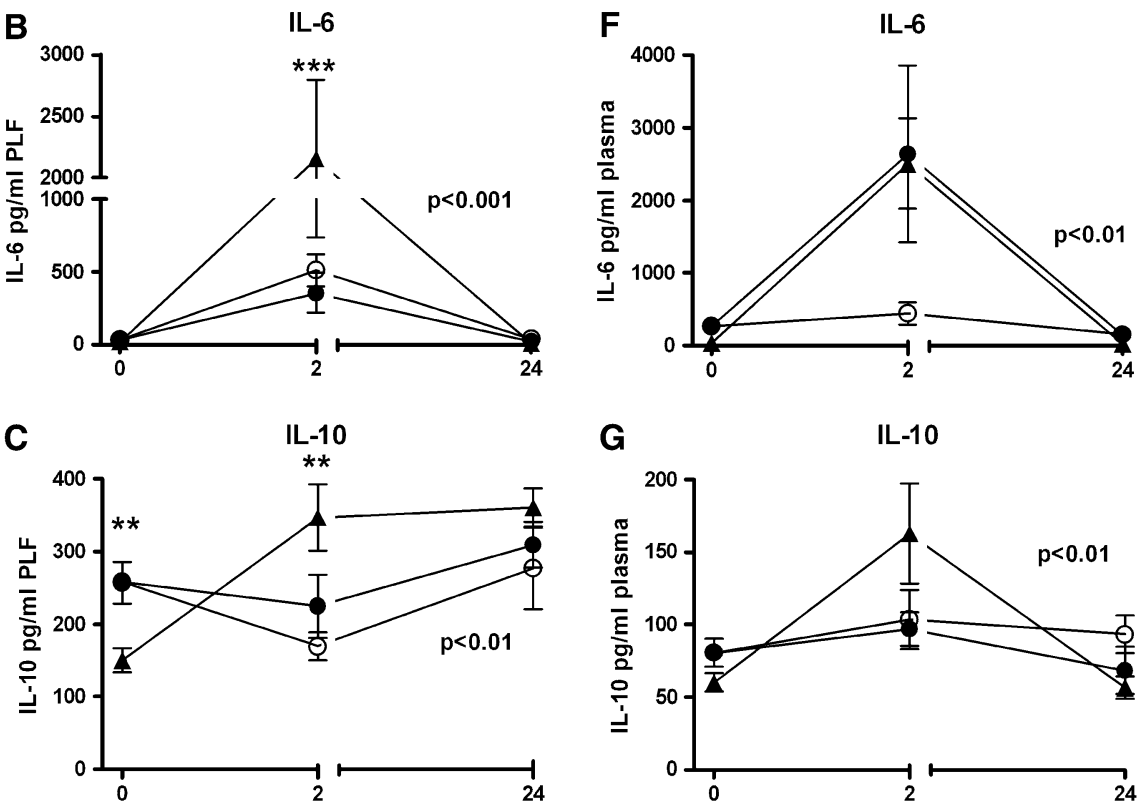

G
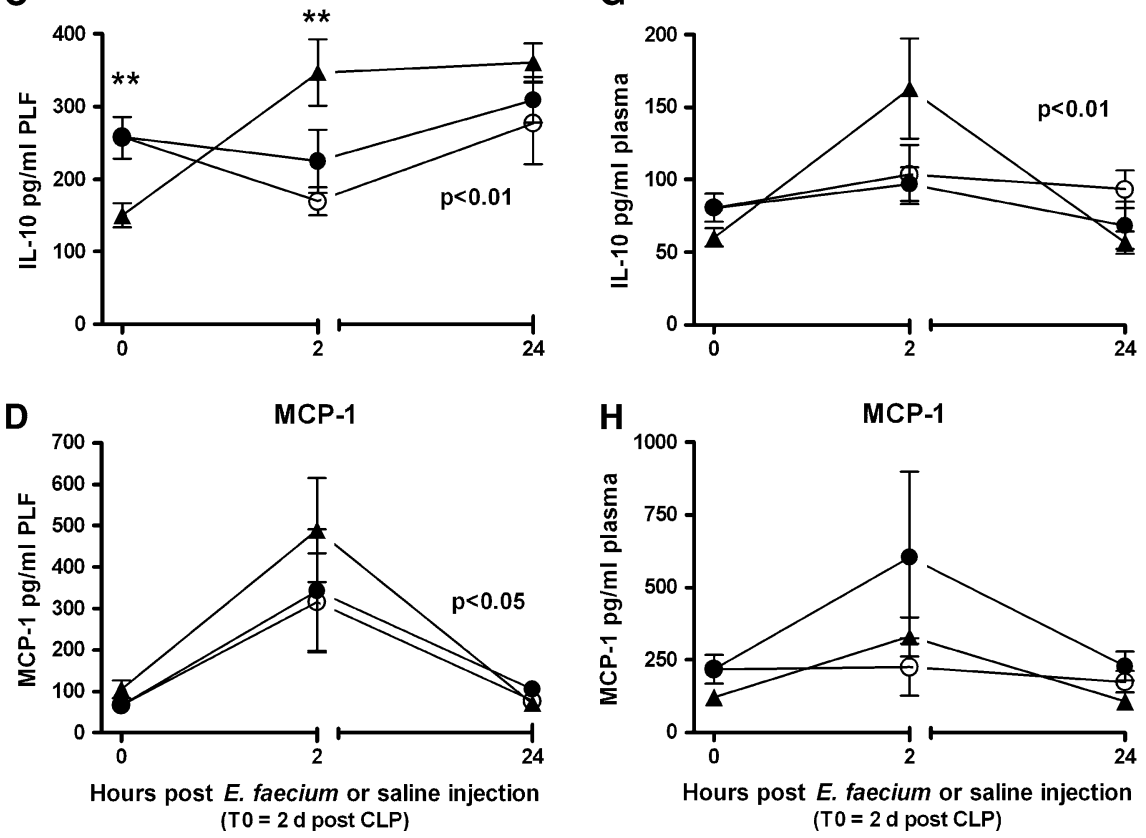

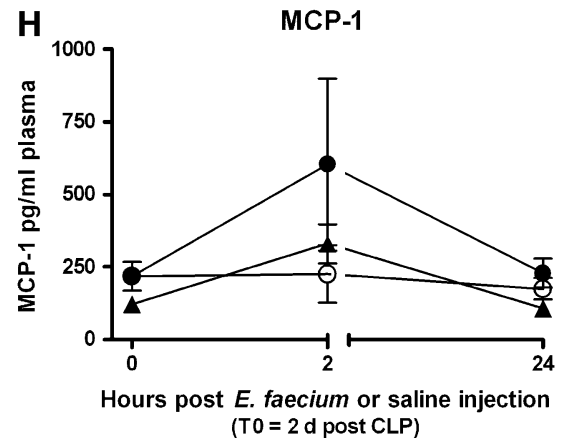

IL-10 and MCP-1 were similar to those measured $48 \mathrm{~h}$ baseline levels at $24 \mathrm{~h}$ after infection, with the exception after sham surgery, except for peritoneal IL-10 levels, of peritoneal IL-10. At 2 and 5 days after infection, the which were higher after CLP (Fig. 3). The levels of these local and systemic concentrations of all mediators meamediators remained low throughout the following 5 days sured were either very low or undetectable (not shown). in CLP mice not infected with VRE. Peritoneal IL-10 Strikingly, in CLP mice peritoneal cytokine levels did not levels decreased from $24 \mathrm{~h}$ after VRE infection onward increase after induction of VRE peritonitis. Interestingly, (not shown). Sham mice displayed an increase in perito- CLP mice demonstrated a comparable increase in plasma neal and plasma concentrations of TNF- $\alpha$, IL-6, IL-10 and TNF- $\alpha$ and IL-6 levels relative to sham mice after MCP-1 $2 \mathrm{~h}$ after infection with VRE; the levels of these infection with VRE. Sham mice not infected with VRE mediators rapidly decreased thereafter, returning to showed low or undetectable cytokine levels throughout 
the experiment; IFN- $\gamma$ and IL-12p70 levels were low or undetectable in any of the mice (not shown).

VRE peritonitis does not impact on host defense against CLP-induced sepsis

Superinfection with VRE did not result in increased CLPinduced lethality: during the 5-day observation period 6\% of CLP mice with subsequent VRE infection died, whereas $8 \%$ of CLP mice with subsequent saline injection died. None of the sham mice died. Furthermore, no differences in weight loss were seen between CLP mice with or without VRE infection (not shown). CLP caused formation of an intra-abdominal abscess surrounding the ligated and perforated cecum, covered by small-bowel loops. No difference in the aspect of the abscess was seen after VRE infection compared to saline injection. No other abscesses were found in the abdominal cavity or organs up to 7 days after CLP. In addition, VRE infection did not influence the gram-negative or gram-positive bacterial loads in PLF, blood, liver or lungs after CLP (shown for total aerobic bacterial loads in fig. 4). Only mild inflammatory changes were seen in liver and lungs upon histopathological examination that did not differ between CLP mice with or without VRE infection (not shown). Nonetheless, CLP did induce hepatocellular injury and a reduced kidney function, as reflected by elevated plasma concentrations of ASAT and creatinine, respectively. However, ASAT and creatinine levels were comparable between CLP mice with or without VRE infection (Fig. 5). No pathology or altered ASAT or creatinine levels were seen in sham mice (not shown).

\section{Discussion}

In this study, we demonstrate that polymicrobial sepsis induced by CLP results in a strongly impaired peritoneal and systemic clearance of VRE, accompanied by a profoundly reduced early inflammatory response at the primary site of VRE infection. Although CLP mice infected with VRE had high enterococcal loads in multiple body sites for days, these animals did not show increased organ damage when compared to CLP mice not infected with VRE, as determined by histopathology of lung and liver tissue and laboratory markers for liver and kidney injury. These data suggest that infection and dissemination of VRE is greatly facilitated by sublethal polymicrobial sepsis, but that - at least in this modelVRE does not contribute to sepsis induced pathology to a significant extent.

Infections with E. faecium are a major problem in patients on intensive care units, and are associated with increased morbidity and mortality [24-26]. These infections are of special concern as they are increasingly difficult to treat due to the escalating antimicrobial resistance expressed by E. faecium [27, 28]. The aforementioned patient groups frequently suffer a period of
Fig. 4 Enterococcus faecium infection does not influence total aerobic bacterial loads after CLP. Nine mice per time point underwent CLP and received $10^{8} \mathrm{CFU}$ E. faecium (closed circles) or saline (open circles) intraperitoneally $48 \mathrm{~h}$ thereafter. Two hours, 1, 2 and 5 days after the second challenge mice were killed. Mean $( \pm$ SEM) CFU of total aerobic bacteria in a peritoneal lavage fluid (PLF), b blood, c liver, and $\mathbf{d}$ lung are shown. During the 5 days of the experiment $6 \%$ of the mice with subsequent VRE infection died, whereas $8 \%$ of the mice with subsequent saline injection died. No differences in aerobic outgrowth were seen between groups
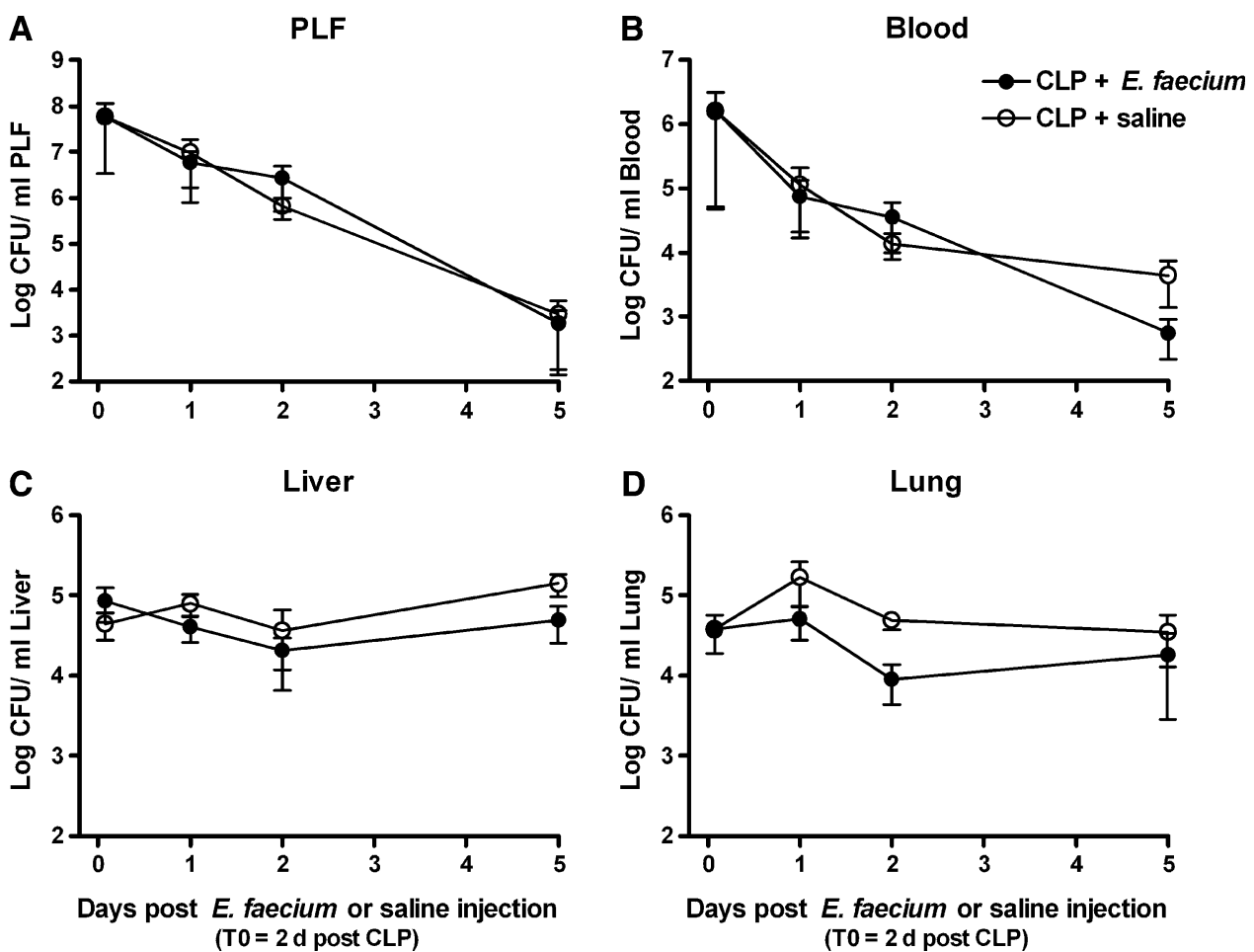

D Lung

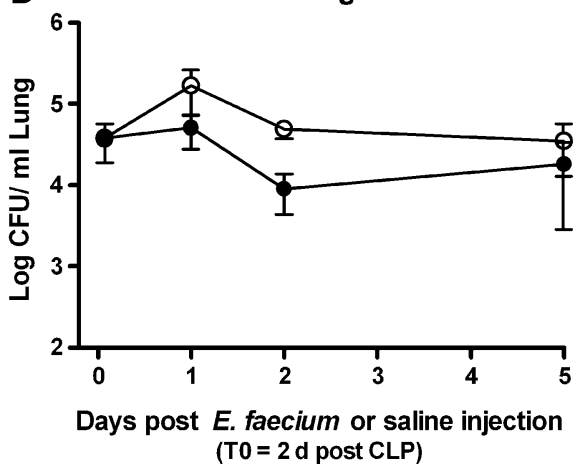




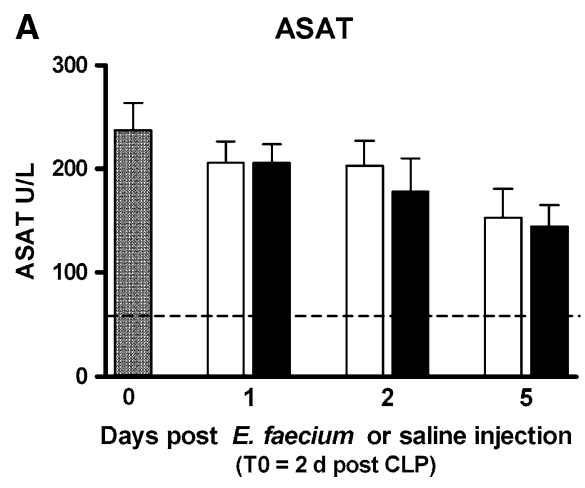

Fig. 5 Enterococcus faecium infection does not impact on CLPinduced hepatocellular injury or renal insufficiency. Nine mice per time point underwent CLP and received $10^{8}$ CFU E. faecium (closed circles) or saline (open circles) intraperitoneally $48 \mathrm{~h}$ thereafter. Mice were killed directly before E. faecium infection (gray bar) and 1,2 and 5 days later. a Plasma concentrations of ASAT and $\mathbf{b}$ creatinine. During the 5 days of the experiment $6 \%$ of

sepsis during their hospital stay. Sepsis has been associated with a vigorous proinflammatory response, which contributes to the multisystem organ failure and mortality $[8,9]$. Additionally, septic insults initiate concurrent or sequential anti-inflammatory cascades, which are important to avoid detrimental inflammatory responses and achieve immunological homeostasis. The anti-inflammatory response has been implicated in the inability of critically ill patients to eradicate the primary infection responsible for sepsis and their propensity to acquire secondary nosocomial infections [6-11].

CLP is considered a clinically relevant model for sepsis since it mimics a common clinical scenario and is associated with an early hyper-inflammatory reaction followed by a subsequent hypo-inflammatory phase [12, 29, 30]. Several studies have documented a reduced capacity to release cytokines after CLP and a subsequent challenge with bacterial antigens [23, 30, 31]. This sepsis-induced immune hyporesponsiveness was shown to impair host defense mechanisms in the lungs against Pseudomonas aeruginosa and Streptococcus pneumoniae [13-15]. We here used the CLP model of sepsis to study the course of VRE peritonitis in a host with severe co-morbid disease. Our main finding was that CLP renders the host less capable of adequately responding to VRE, as reflected by a diminished capacity to recruit neutrophils to the site of the infection and to locally release chemokines and cytokines, which resulted in a strongly reduced enterococcal clearance from the peritoneal cavity and subsequent dissemination. We measured increased peritoneal IL-10 levels $48 \mathrm{~h}$ after CLP, directly before VRE infection. Considering that IL-10 is an anti-inflammatory cytokine capable of inhibiting the production of proinflammatory mediators $[32,33]$, this in part may explain the reduced

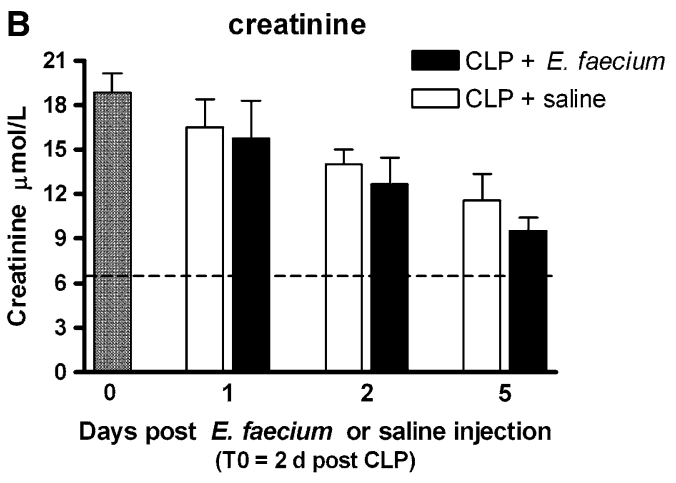

the mice with subsequent VRE infection died, whereas $8 \%$ of the mice with subsequent saline injection died. Data are means \pm SEM. Dotted horizontal lines represent mean values of healthy mice $(N=8)$. All values measured after CLP were higher than healthy control values; differences between CLP mice with and without $E$. faecium infection were not significant

release of cytokines and chemokines into the peritoneal cavity of CLP mice infected with VRE. Other factors implicated in CLP induced immune suppression include enhanced apoptosis of immune cells and increased expression of inhibitors of Toll-like receptors [8, 9, 30, 34].

Sham operated control mice demonstrated an early inflammatory response and a rapid clearance of VRE similar to what we reported earlier in previously healthy mice that had not been subjected to abdominal surgery [18]. Hence, abdominal surgery per se does not appear to have a major impact on host defense against VRE, at least in this model.

Experimental studies have suggested that E. faecalis can influence abscess formation [35]. In our study we were unable to demonstrate that prolonged infection with VRE influences abscess formation, morbidity, mortality or organ damage in mice subjected to CLP. In addition, VRE infection did not impact on bacterial burdens associated with CLP. As such, our data argue against a causal role for VRE in adverse clinical outcomes in patients infected with this bacterium. We have to mention, however, that the mice used were healthy before going into surgery and 10 weeks of age resembling a situation of mid- to late-adolescence in humans. Additionally, the intensity of polymicrobial sepsis in this CLP model was relatively mild. It would be of interest to examine the impact of VRE infections in other models with diverse underlying illnesses, e.g., by using older male/female mice, being in an immunocompromised state before performing surgery.

However, our results clearly show that the host suffering from sublethal polymicrobial sepsis induced by CLP is severely impaired in clearing abdominal and systemic VRE infection, most likely due to an incapacity 
to respond to this bacterium at the primary site of infection.

Acknowledgments The authors like to thank J. Daalhuisen, M. ten Brink and R. de Beer for their expert technical assistance.
Open Access This article is distributed under the terms of the Creative Commons Attribution Noncommercial License which permits any noncommercial use, distribution, and reproduction in any medium, provided the original author(s) and source are credited.

\section{References}

1. Willems RJ, Bonten MJ (2007) Glycopeptide-resistant enterococci: deciphering virulence, resistance and epidemicity. Curr Opin Infect Dis 20:384-390

2. Malani PN, Kauffman CA, Zervos MJ (2002) Enterococcal disease, epidemioloy, and treatment. In: Gilmore (ed) The enterococci: pathogenesis, molecular biology, and antibiotic resistance, 1 st edn. ASM, Washington, DC, pp 385-408

3. Caballero-Granado FJ, Becerril B, Cisneros JM, Cuberos L, Moreno I, Pachon J (2001) Case-control study of risk factors for the development of enterococcal bacteremia. Eur J Clin Microbiol Infect Dis 20:83-90

4. Lautenbach E, Bilker WB, Brennan PJ (1999) Enterococcal bacteremia: risk factors for vancomycin resistance and predictors of mortality. Infect Control Hosp Epidemiol 20:318-323

5. Kox WJ, Volk T, Kox SN, Volk HD (2000) Immunomodulatory therapies in sepsis. Intensive Care Med 26(Suppl 1):S124-S128

6. Volk HD, Reinke P, Krausch D, Zuckermann H, Asadullah K, Muller JM, Docke WD, Kox WJ (1996) Monocyte deactivation-rationale for a new therapeutic strategy in sepsis. Intensive Care Med 22(Suppl 4):S474S481

7. Volk HD, Reinke P, Docke WD (2000) Clinical aspects: from systemic inflammation to 'immunoparalysis'. Chem Immunol 74:162-177

8. Hotchkiss RS, Karl IE (2003) The pathophysiology and treatment of sepsis. N Engl J Med 348:138-150

9. van der Poll T, Opal SM (2008) Hostpathogen interactions in sepsis. Lancet Infect Dis 8:32-43

10. Fumeaux T, Dufour J, Stern S, Pugin J (2004) Immune monitoring of patients with septic shock by measurement of intraleukocyte cytokines. Intensive Care Med 30:2028-2037

11. Monneret G, Lepape A, Voirin N, Bohe J, Venet F, Debard AL, Thizy H, Bienvenu J, Gueyffier F, Vanhems P (2006) Persisting low monocyte human leukocyte antigen-DR expression predicts mortality in septic shock. Intensive Care Med 32:1175-1183
12. Wichterman KA, Baue AE, Chaudry IH (1980) Sepsis and septic shock-a review of laboratory models and a proposal. J Surg Res 29:189-201

13. Deng JC, Cheng G, Newstead MW, Zeng X, Kobayashi K, Flavell RA, Standiford TJ (2006) Sepsis-induced suppression of lung innate immunity is mediated by IRAK-M. J Clin Invest 116:2532-2542

14. Muenzer JT, Davis CG, Dunne BS, Unsinger J, Dunne WM, Hotchkiss RS (2006) Pneumonia after cecal ligation and puncture: a clinically relevant "two-hit" model of sepsis. Shock 26:565-570

15. Steinhauser ML, Hogaboam CM, Kunkel SL, Lukacs NW, Strieter RM, Standiford TJ (1999) IL-10 is a major mediator of sepsis-induced impairment in lung antibacterial host defense. J Immunol 162:392-399

16. Montravers P, Gauzit R, Muller C, Marmuse JP, Fichelle A, Desmonts JM (1996) Emergence of antibioticresistant bacteria in cases of peritonitis after intraabdominal surgery affects the efficacy of empirical antimicrobial therapy. Clin Infect Dis 23:486-494

17. Murray BE (1990) The life and times of the Enterococcus. Clin Microbiol Rev 3:46-65

18. Leendertse M, Willems RJ, Giebelen IA, van den Pangaart PS, Wiersinga WJ, de Vos AF, Florquin S, Bonten MJ, van der Poll T (2008) TLR2-Dependent MyD88 signaling contributes to early host defense in Murine Enterococcus faecium Peritonitis. J Immunol 180:4865-4874

19. van Veen SQ, van Vliet AK, Wulferink M, Brands R, Boermeester MA, van Gulik TM (2005) Bovine intestinal alkaline phosphatase attenuates the inflammatory response in secondary peritonitis in mice. Infect Immun 73:4309-4314

20. Willems RJ, Top J, van Santen M, Robinson DA, Coque TM, Baquero F, Grundmann H, Bonten MJ (2005) Global spread of vancomycin-resistant Enterococcus faecium from distinct nosocomial genetic complex. Emerg Infect Dis 11:821-828
21. Hendrickx AP, van Wamel WJ, Posthuma G, Bonten MJ, Willems RJ (2007) Five genes encoding surfaceexposed LPXTG proteins are enriched in hospital-adapted Enterococcus faecium clonal complex 17 isolates. $\mathbf{J}$ Bacteriol 189:8321-8332

22. Renckens R, Roelofs JJ, ter Horst SA, van 't Veer C, Havik SR, Florquin S, Wagenaar GT, Meijers JC, van der Poll $\mathrm{T}$ (2005) Absence of thrombinactivatable fibrinolysis inhibitor protects against sepsis-induced liver injury in mice. J Immunol 175:67646771

23. Xiao H, Siddiqui J, Remick DG (2006) Mechanisms of mortality in early and late sepsis. Infect Immun 74:5227-5235

24. DiazGranados CA, Jernigan JA (2005) Impact of vancomycin resistance on mortality among patients with neutropenia and enterococcal bloodstream infection. J Infect Dis 191:588-595

25. Vergis EN, Hayden MK, Chow JW, Snydman DR, Zervos MJ, Linden PK, Wagener MM, Schmitt B, Muder RR (2001) Determinants of vancomycin resistance and mortality rates in enterococcal bacteremia a prospective multicenter study. Ann Intern Med 135:484-492

26. Landry SL, Kaiser DL, Wenzel RP (1989) Hospital stay and mortality attributed to nosocomial enterococcal bacteremia: a controlled study. Am J Infect Control 17:323-329

27. Treitman AN, Yarnold PR, Warren J, Noskin GA (2005) Emerging incidence of Enterococcus faecium among hospital isolates (1993 to 2002). J Clin Microbiol 43:462-463

28. Leavis HL, Bonten MJ, Willems RJ (2006) Identification of high-risk enterococcal clonal complexes: global dispersion and antibiotic resistance. Curr Opin Microbiol 9:454-460

29. Deitch EA (1998) Animal models of sepsis and shock: a review and lessons learned. Shock 9:1-11

30. Ayala A, Chaudry IH (1996) Immune dysfunction in murine polymicrobial sepsis: mediators, macrophages, lymphocytes and apoptosis. Shock 6(Suppl 1):S27-S38 
31. Wang X, Ebong SJ, Call DR, Newcomb DE, Bolgos GR, Remick DG (2002)

Calcitonin gene-related peptide partially reverses decreased production of chemokines KC and MIP-2

following murine sepsis. Inflammation 26:167-174

32. Fiorentino DF, Zlotnik A, Mosmann TR, Howard M, O'Garra A (1991) IL10 inhibits cytokine production by activated macrophages. J Immunol 147:3815-3822
33. van der Poll T, van Deventer SJ (1999) Cytokines and anticytokines in the pathogenesis of sepsis. Infect Dis Clin North Am 13:413-426

34. Liew FY, Xu D, Brint EK, O'Neill LA (2005) Negative regulation of toll-like receptor-mediated immune responses. Nat Rev Immunol 5:446-458
35. Onderdonk AB, Bartlett JG, Louie T, Sullivan-Seigler N, Gorbach SL (1976) Microbial synergy in experimental intra-abdominal abscess. Infect Immun 13:22-26 